Open Access

\title{
Efficient, helpful, or distracting? A literature review of media multitasking in relation to academic performance
}

Kaitlyn E. May ${ }^{1 *}$ and Anastasia D. Elder ${ }^{2}$

\author{
* Correspondence: \\ kmay3@crimson.ua.edu \\ ${ }^{1}$ Department of Educational Studies \\ in Psychology, Research \\ Methodology, and Counseling, \\ University of Alabama, Tuscaloosa, \\ AL 07203, USA \\ Full list of author information is \\ available at the end of the article
}

\begin{abstract}
Media multitasking, using two or more medias concurrently, prevails among adolescents and emerging adults. The inherent mental habits of media multitasking — dividing attention, switching attention, and maintaining multiple trains of thought - have significant implications and consequences for students' academic performance. The goal of this review is to synthesize research on the impacts of media multitasking on academic performance. The research indicates that media multitasking interferes with attention and working memory, negatively affecting GPA, test performance, recall, reading comprehension, note-taking, self-regulation, and efficiency. These effects have been demonstrated during in- class activities (largely lectures) and while students are studying. In addition, students struggle to accurately assess the impact media multitasking will have on their academic performance. Further research should attend to understanding effects of media multitasking in more diverse instructional contexts and for varied academic tasks. Fostering students' self-regulation around media multitasking is a promising area for future efforts towards improving academic performance of college students.
\end{abstract}

Keywords: Media multitasking, Cognition, Academic performance, Multitasking

\section{Introduction}

According to the Kaiser Family Foundation (2010), media use is the dominant way adolescents and young adults spend their time, averaging more than $7.5 \mathrm{~h}$ of use daily-almost the equivalent in length of a full work day (Roberts, Foehr, \& Rideout, 2010). Students increase media absorption by using two or more mediums simultaneously via media multitasking, experiencing $10 \mathrm{~h}$ and $45 \mathrm{~min}$ of media content within their daily $7.5 \mathrm{~h}$. This behavior carries into college, where media use is largely unregulated. Hwang, Kim, and Jeong (2014) found that $90 \%$ of university students multitask when using media, and that more than half of time spent on media involves multitasking. Junco (2012) found that $69 \%$ of students reported text messaging during class, $28 \%$ reported using Facebook and email in class, with $21 \%$ using the mediums for off-task purposes. An examination of 3372 self-directed computer sessions by 1249 students via time logs revealed that $99 \%$ of sessions involved some multitasking (Judd, 2014).

College students commonly but erroneously report that multitasking increases productivity (Lin, Cockerham, Chang, \& Natividad, 2015). Other students multitask on a

(c) The Author(s). 2018 Open Access This article is distributed under the terms of the Creative Commons Attribution 4.0 International License (http://creativecommons.org/licenses/by/4.0/), which permits unrestricted use, distribution, and reproduction in any medium, provided you give appropriate credit to the original author(s) and the source, provide a link to the Creative Commons license, and indicate if changes were made. 
situational basis according to motive. A student with a specific goal and sufficient motivation, such as studying for an upcoming exam in a difficult class, is less likely to multitask. On the other hand, students with less consequential goals, such as communicating with friends for leisure via Facebook or email, are more likely to multitask (Judd \& Kennedy, 2011).

The ubiquity of media multitasking among today's students raises concerns about its consequences and outcomes in relation to student learning and cognition. The aim of this paper is to synthesize existing research on the effects of media multitasking on academic performance, and to highlight implications for students and educators. This paper reviews pertinent theories and analyzes research evidence for the effects of media multitasking on aspects related to cognitive functioning in academic performance, including grade point average (GPA), efficiency, reading comprehension, self-regulation, and test performance. An initial review of the literature was conducted in the fall of 2015 through the PsychInfo database. An additional literature search was conducted in the summer of 2017, and a final search in the fall of 2017 during revisions to ensure comprehensiveness. Search words and phrases included media multitasking, cognition, multitasking, academic performance, and self-regulation. A "snowball" method of using the most recent works to find citations provided in them was used. This review analyzed 38 articles from 2003 to 2017 that primarily investigated academic effects of media multitasking habits of college-aged students. Articles were excluded if they did not involve multitasking but rather generalized media use, if they were published prior to 2000 (with the exception of theoretical articles), or if they were not primarily focused on investigating effects of multitasking on academic performance.

\section{Cognitive functioning while multitasking: Theoretical foundation}

Multitasking may impair learning through rapid use of the limited capacity of learners' information processing channels, especially attention processes, leaving insufficient space for meaningful learning. This is based in information processing theory, the scattered attention hypothesis, and bottleneck theory in which attention is a limited resource (Maslovat et al., 2013; Van dur Schuur, Baumgartner, Sumter, \& Valkenburg, 2015). The term 'attention' refers to how individuals actively process specific information in their environment. Attention is selective and enhances processing of the attended stimulus while diminishing processing of unattended stimuli. Collectively, these theories serve to elucidate the manner in which media multitasking decreases academic performance and impacts cognition.

\section{Theories of attention}

According to the bottleneck theory of attention, attention can be allocated to only one task at a time. Thus, multitasking is a myth; instead, the mind switches between tasks. Stimuli arrives at a processing 'bottleneck', at which only one item can be processed at a time (Broadbent, 1958; Maslovat et al., 2013). Because attentional resources are limited, filtering of stimuli must occur. The bottleneck postpones aspects of processing of the secondary task until the primary task is completed.

Van dur Schuur and colleagues (van dur Schuur et al., 2015) suggest two opposing consequences of media multitasking with regards to cognitive control, which they 
referred to as the scattered attention and trained attention hypotheses. According to the scattered attention hypothesis, long-term media multitasking may lead to disrupted cognitive control in which the individual gravitates towards the preferred task rather than maintaining focus despite attentional distractions (van dur Schuur et al., 2015). Cognitive control includes several processes, such as focusing attention on goalrelevant information, filtering irrelevant information, switching efficiently between tasks, and retaining information temporarily (van dur Schuur et al., 2015; Uncapher, Thieu, \& Wagner, 2016). Engaging in multiple tasks highly demands attentional capacity, resulting in deficits in cognitive control (Chinchanachokchai, Duff, \& Sar, 2015; Miller \& Cohen, 2001; Ophir, Nass, \& Wagner, 2009; van dur Schuur et al., 2015). Thus, multitasking reduces performance by causing interference, distraction, and ultimately errors (Courage, Bakhtiar, Fitzpatrick, Kenny, \& Brandeau, 2015).

The scattered attention hypothesis maintains the information processing theoretical approach to cognition, in which the brain is a device that employs mental resources to carry out operations and complete tasks. According to this theory, the executive system controls mental resources, allocating them where necessary. Per information processing theory, attention is a limited resource. According to the scattered attention hypothesis, media multitasking hastens the depletion of the attentional resource, consequently diminishing performance on the primary task. If-as is the case with media multitasking-attentional demand exceeds attentional capacity, the cognitive system overloads and performance suffers.

On the other hand, the trained attention hypothesis argues that frequent media multitasking could positively affect cognitive control via eventual training and improvement of control processes. According to this theory, multitasking promotes mental flexibility that enables high-level efficiency and productivity, skills essential for success in modern work and learning environments (Courage et al., 2015). The trained attention hypothesis asserts that ability to filter irrelevant information could improve through frequent practice multitasking (Alzahabi \& Becker, 2013; Ophir et al., 2009). Research is more consistent with the scattered attention hypothesis than the trained attention hypothesis (van der Schuur et al., 2015). This is because experimental literature to date on divided attention and dual-task performance demonstrates a limited processing system and consequential deterioration in performance and productivity when multitasking (Courage et al., 2015). Nevertheless, examination of distractor filtering in multitaskers of various frequencies presents a difference in performance, pointing to the potential validity of the trained attention hypothesis (Cain \& Mitroff, 2011). Heavy and low media multitaskers (categorized by media multitasking index score via the Media Use Questionnaire; Ophir et al., 2009) completed a singleton distractor task with low working-memory demands. Students who were not frequent media multitaskers relied on top-down information to complete the experimental task, applying top-down distraction filtering to improve performance. Frequent media multitaskers, on the other hand, attended to and processed stimuli to the same degree regardless of whether or not the presented stimuli could be the target. Cain and Mitroff (2011) argue that the difference in performance on the attentional task affirm attentional differences in heavy media multitaskers; thus, frequent media multitaskers may maintain a wider attentional scope which allows attention to more visual information compared to infrequent multitaskers who maintain a narrower attentional scope. 


\section{Working memory theories}

Theories of working memory also provide insight to the cognition of media multitasking. Attention biases towards objects that match the current contents of visual working memory (Hollingworth \& Beck, 2016). Visual working memory is a cognitive system that holds a limited amount of visual information in a temporary storage buffer so that it may be accessed to efficiently achieve goals. Recent research points to working memory as a predictor of multitasking ability, more so than other cognitive, personality, and experience-based variables. For example, Cain, Leonard, Gabrieli, and Finn (2016) found that frequent media multitasking was associated with poorer performance on behavioral measures of working memory capacity. However, studies like that of Cain et al. (2016) rely on dual-task measures of working memory. Thus, Redick (2016) examined whether working memory measures must be dual-tasks to predict multitasking performance, finding that singletask working memory measures also predict multitasking performance. Accordingly, the relationship between working memory and multitasking is independent of the method of task used to assess working memory. This indicates that working memory is perhaps fundamental to individual multitasking ability.

This paper relies on the aforementioned models to examine the cognitive impact of media multitasking within the frame of a theoretical foundation, as well as to highlight existing evidence related to academic performance that confirm or oppose the discussed theories.

\section{Multitasking effects related to academic performance}

Empirical studies firmly establish a significant drop in academic performance due to media multitasking. According to the Kaiser Family Foundation, heavy media users (exposed to more than $16 \mathrm{~h}$ of media content per day, often via media multitasking) report receiving C's or lower in school, getting in trouble often, frequently feeling sad or unhappy, and frequent boredom (Roberts et al., 2010). Survey data found frequent in-class multitaskers have lower current college GPAs (Al-Menayes, 2015; Bellur, Nowak, \& Hull, 2015; Clayson \& Haley, 2012; Junco, 2012; Lau, 2017). A longitudinal study examining women's media use during their first year of college and associations with academic outcomes found that women reported nearly $12 \mathrm{~h}$ of media use per day (Walsh, Fielder, Carey, \& Carey, 2013). Such amounts of media use imply multitasking; further, media use was negatively related to academic outcomes after controlling for demographics and prior academics, and there were significant, indirect effects of social networking on GPA.

\section{In-class multitasking}

In-class, mobile phone multitasking during direct instruction is heavily researched, as it is the technology of choice for many university students and the most prevalent. Rosen, Lim, Carrier, and Cheever (2011) examined the impact of in-class mobile phone usage during course lecture on test performance. Students responded to messages sent by researchers at even intervals throughout a 30-min videotaped lecture (Rosen et al., 2011). Students in the high text messaging group performed worse by one letter grade on an information post-test than the low text messaging group (10.6\% lower score). However, the moderate text messaging group showed no score difference compared to the other 
two groups. Participants who received and sent more words in their texts performed worse on the test; however, this was moderated by elapsed time between receiving and sending a text, with longer delays resulting in better performance. Student metacognitive self-reports reflected test results. Nearly three-fourths of participants felt that receiving and sending text messages during class was disruptive to learning. Despite this, $40 \%$ felt it was acceptable to text in class.

Similar studies comparing test performance found the non-texting group outperformed regardless of gender and G.P.A. (Ellis, Daniels, \& Jauregui, 2010; Froese et al., 2010). Ellis et al. (2010) examined the effect of texting multitasking on the grade performance of business students. Participants listened to a class lecture in a texting or no-texting condition. Scores on a post-lecture assessment indicated that exam scores of texting students were significantly lower. In a similar lecture format, Froese et al. (2010) demonstrated that students lost roughly $30 \%$ of accuracy on a quiz when texting.

A related study found similar results (Kuznekoff \& Titsworth, 2013). Participants in three groups (non-multitasking, low-distraction, and high-distraction) watched a video lecture while taking notes and completed two post-lecture assessments. Students in the non-multitasking control group wrote down $62 \%$ more information, took notes with more details, were able to recall more detailed information, and scored a full letter grade and a half higher than students in the low-distraction and high-distraction groups. Further analysis found that message content influenced effect on class performance. In addition to participants who did not text, participants who sent texts related to the lecture earned a $10-17 \%$ higher letter grade, scored $70 \%$ higher on information recall, and scored $50 \%$ higher on note-taking than students sending texts unrelated to lecture content (Kuznekoff, Munz, \& Titsworth, 2015). These results point to the purpose of usage, rather than multitasking itself, as the culprit for the negative effects of media multitasking on classroom performance. Thus, distinguishing on-task from offtask multitasking redefines the pragmatics of the in-class technology debate.

McDonald (2013) assessed the effect of three different in-class texting behaviors on course grade: (1) mild texting policy; "cell phones are to be turned off and not used during class. This is an issue of respect for others and your professor"; (2) strict cell phone policy; "students will lose $3 \%$ of their final grade each time they are caught texting"; (3) no presented texting policy; "students free to have cell phones on and text as desired" (McDonald, 2013, pg. 36). McDonald (2013) found a negative correlation between in-class texting and final grade score, regardless of texting condition. This negative correlation remained after controlling for GPA, ACT, and attendance. However, the higher the levels of in-class texting behavior by a student, the lower their final grade. In-class texting behavior contributed to $22 \%$ of the predictor value in final grade. This points to the potential of classroom policy to diminish, but not eliminate, the negative effects of in-class media multitasking.

A similar experiment examining in-class media multitasking with classroom performance expanded the experimental variables to reflect individualized preferences for both media use and notetaking (Wood et al., 2012). The study compared multitasking activities of various mediums to three methods of notetaking during a direct instruction lecture. Technological mediums assessed included texting, emailing, Instant Messaging (IM), and Facebook. All media use was for off-task purposes. Note-taking conditions were paper-and-pencil, word-processing, and a natural use of technology condition in 
which participants were allowed to use any technology they wished. The natural use of technology condition served to determine whether students choose to multitask during lectures, what technologies students tend to use, and how the choice to multitask affected learning. Across all sessions, only seven participants did not use technology at all. Almost half of participants used technology for every class when permitted. The experiment was conducted over three consecutive lectures. Results indicated that participants who did not use any technologies outperformed students who did multitask-regardless of mediumon a 15-item multiple-choice test. Participants in the Facebook and Instant Messaging conditions performed more poorly than those in the paper-and-pencil control. Wood et al. (2012) surmised that Facebook and IM were more likely to serve as distractors that yield negative impact on learning. Repeated practice with the various technologies did not improve performance over time in any condition.

Downs, Tran, McMenemy, and Abegaze (2015) manipulated the multitasking environment rather than the note-taking method, finding that participants performed worst on a post-lecture exam when distracted with social media. Two-hundred and four university students were randomly assigned to one of six classroom conditions: (1) Facebook distracted; (2) paper note-taking; (3) no media use control group; (4) mixed distraction; (5) laptop note-taking; and (6) distracted combination. Participants in the Facebook condition used laptops to join a Facebook chat group created for the study through which they received questions to respond to at two-minute intervals. Participants in the note-taking condition received a sheet of notebook paper and instructions to take notes as they normally would during a lecture. Participants in the no media use control group were instructed to only watch the documentary. The mixed distraction group approximately half of the participants (every other seat) were asked to join the aforementioned Facebook chat group, while the other half watched the documentary without an additional distraction. Participants in the laptop note-taking group used a word processing program to take notes. Participants in the distracted combination condition followed the Facebook protocol for condition one while simultaneously taking notes on their laptop during the video. In all conditions, participants viewed a documentary video for $25 \mathrm{~min}$ and completed a subsequent, 15-question, multiple-choice exam assessing lecture content. Participants in distracted conditions (1, 4, \& 6) performed worse on the post-test than participants in the non-distracted control, paper-and-pencil, and laptop note-taking groups.

Brooks (2015) further examined mobile phone multitasking in a natural classroom setting. Participants completed a pre-task survey before watching a 15-min video lecture. Participants received no instructions or study regarding social media or mobile phone usage prior to observing a 15-min video lecture. Following the video, participants completed a quiz over video content and a survey regarding social media use, attentional control, multitasking computer self-efficacy, technostress, and happiness. Participants were instructed to complete the tasks on their own time so that they would have access to their personal machines. Like prior studies, this study found that social media usage on mobile phones negatively affected performance. Attentional control and multitasking computer self-efficacy did not yield significant effect on this relationship. Thus, students are not as skilled at multitasking as they perceive themselves to be.

Conard and Marsh (2014) examined the effect of interruptions via Instant Messaging and situational interest on learning during multitasking. Participants viewed a video 
presentation in a simulated environment meant to emulate a standard working environment such as a business meeting, a training presentation, or a classroom lecture. During the 16-min video, participants responded to eight Instant Messages sent at specific times by research assistants. Following the video, participants completed a 22-item multiple choice test assessing lecture comprehension and responded to measure of situational interest. Multitasking interruptions reduced learning; furthermore, interest level was as strong a predictor of learning as being interrupted. However, interest did not moderate the effect of interruptions. This indicates a need for further research examining individual difference factors, such as interest levels, when assessing the effects of multitasking on learning.

Like mobile phone use, laptop use is commonplace in the university setting, yet presents unique issues concerning multitasking. Laptops provide a convenient means to connect with the lecture while simultaneously providing a major source of distraction. Self-report data by Fried (2008) showed that students using laptops in class spent considerable time multitasking. On average, students generate more than 65 new active windows on laptops per lecture, with $62 \%$ of these windows being classified as distractive and irrelevant to lecture content (Kraushaar \& Novak, 2010). Laptop use negatively related to multiple learning outcomes including course grade, focus on lectures, reported clarity of lectures, exam performance, and comprehension (Fried, 2008; Kraushaar \& Novak, 2010; Wood et al., 2012; Zhang, 2015). In a study by Hembrooke and Gay (2003), laptop use during lecture resulted in significantly lower recall and recognition test scores. Students in two conditions (laptop multitasking or no multitasking condition) listened to a lecture and completed a comprehension exam. Exam results indicated that multitasking students suffered memory decrements.

Students habitually using laptops in class report low satisfaction with their education, are more likely to multitask in class, and are more distracted (Wurst, Smarkola, \& Gaffney, 2008). According to information processing theory, humans process stimuli, rather than merely responding, employing attention mechanisms such as working memory. Thus, laptops provide additional stimuli for students to process, distracting them from the academic task. This accounts for the decrements in performance seen as a result of in-class laptop multitasking. Because most technological mediums serve as a gateway to both productive and unproductive tasks, students are likely to engage in both over the course of a class period and struggle to resist temptation. These distractions prevent processing and learning of material.

Research involving undergraduate students indicate that laptop multitasking can hinder class learning for both users and nearby peers (Fried, 2008; Sana, Weston, \& Cepeda, 2013). Fried (2008) administered surveys to a university course, assessing various aspects of class such as class attendance, classroom experiences, and laptop use, finding that students frequently cited personal and external laptop use as major sources of classroom distractions and hindrances of learning. Experimental evidence affirms this: Sana et al. (2013) simulated a classroom with 40 undergraduate students in which students viewed a 45-min PowerPoint lecture in a multitasking or non-multitasking condition and completed a multiple-choice comprehension test. Participants who multitasked on a laptop during lecture scored lower on the test than non-multitaskers. Moreover, participants in direct view of a multitasking peer scored 17\% lower than those who were not. Distractions due to movement of images and laptop screen 
lighting, as well as multitasking activities, may cause involuntary shifts of attention among students in close proximity to laptop users. Thus, proximity to a multitasker-and not solely active multitasking - can be detrimental to academic performance. Understanding the effects of multitasking on others is an area of research deserving replication and further investigation.

Overall, this body of research regarding in-class multitasking affirms ideas purported by the bottleneck theory of attention as well as the scattered attention hypothesis, and presents evidence against the trained attention hypothesis. The literature indicates that attempting to attend to class material (mostly lectures) and engage in technologies simultaneously can have a detrimental impact on learning, likely due to inattention to course information. These negative effects on academics were demonstrated with varied outcomes- test performance, grades, comprehension, recall, and note-taking. Yet, many of these studies involved measuring the impact of media multitasking during a short time span, so longer follow-up studies are needed to more fully investigate the claims of the trained attention hypothesis which states that repeated practice of media multitasking will improve performance over time.

\section{Multitasking outside of class}

Laptops and mobile phones are particularly distracting while studying or doing coursework outside of class, as students can easily access alternate media sources such as email, Facebook, or Instant Messaging (IM) on them. Much of the research to date primarily assessed the impact of media multitasking on in-class activities, such as test performance. Few studies have examined the role of media multitasking on assignments outside of class, such as homework or studying. A survey study of 1839 students revealed that using Facebook while doing schoolwork was negatively predictive of overall semester GPA. (Junco, 2012). Junco and Cotten (2012) surmised that Facebook or texting while completing schoolwork may tax students' capacity for cognitive processing, inhibiting deeper learning. According to one experimental study, the more time participants reported spending on IM in class, the lower self-reported GPA. (Fox, Rosen, \& Crawford, 2009).

Outside of the classroom, mobile phone use is negatively associated with academic performance. Texting while studying was significantly and negatively associated with college GPA after controlling for demographic variables, self-efficacy for self-regulated learning, self-efficacy for academic achievement, and high school GPA (Junco, 2012; Junco \& Cotten, 2012; Lepp, Barkley, \& Karpinski, 2015). Amount of texting and texting while multitasking was negatively predictive of overall GPA for U.S. students (Karpinski, Kirschner, Ozer, Mellott, \& Ochwo, 2013). Students who did not text while studying had a higher GPA than those who did text. Furthermore, GPA was higher for those who spent fewer minutes texting per day compared to increased levels of texting. Similar effects are elicited by other digital media technologies. Students' media multitasking with various digital media technologies, including social networking platforms while studying suffer negative consequences. Students who used fewer forms of media multitasking (0-2 mediums) outperformed students who used more forms ( 7 or more mediums) on exam scores (Patterson, 2017). Yet, the amount of studying time between the two groups of students did not differ. 
An experimental paradigm comparing the effect of laptop multitasking on reading comprehension and task performance cited differential effects (Subrahmanyam et al., 2013). The study comprised of two paradigms. In the first, participants read two passages of low and high difficulty on paper, a laptop, or on a tablet, in a multitasking or non-multitasking condition. Similar to the studies discussed above, neither medium nor multitasking condition affected reading comprehension; however, multitaskers demonstrated markedly reduced efficiency. In the second paradigm, participants synthesized multiple materials and wrote a one-page report. Sources were provided either on paper, on a computer screen without Internet or printer access, or on a computer screen with Internet and printer access. Source materials produced no differences in report quality or efficiency, despite students reporting a preference for paper sources. However, report quality was significantly improved when participants had sources on a computer without Internet compared to a computer with Internet access. Furthermore, active use of paper for note-taking greatly reduced the negative impact of Internet access.

Hence, it appears that these effects are not limited to learning while just attending class, but that media multitasking has harmful effects as students engage in learning activities outside the classroom, too. Multitasking outside of class - while completing homework or studying - is similar to multitasking during class; it requires task-switching, may overload students' capacity for cognitive processing and hence preclude deeper learning. As in bottleneck theory, incoming information arrives at a processing bottleneck, at which only one item can be processed at a time. The consequence of this is diminished performance. According to the scattered attention hypothesis (van dur Schuur et al., 2015) media multitasking negatively affects cognitive control through distraction from the primary activity. Engaging in multiple tasks highly demands attentional capacity, resulting in deficits in performance. Multitasking reduces performance by causing interference, distraction, and errors. Thus, effects of multitasking outside of class parallel those of multitasking within the classroom.

\section{Perceptions of multitasking and self-regulation}

One important aspect for understanding multitasking while engaged in learning activities for class is the issue of students' beliefs and perceptions surrounding multitasking. In Downs et al. (2015) study, participants completed a pre-test examining their perceptions of their multitasking abilities. The same questionnaire was administered following a multiple-choice exam. Participants in various conditions (e.g. distracted by social media and/or taking notes) reported significantly less confidence in their ability to effectively multitask. This is particularly interesting considering students never received their individual scores on the multiple-choice assessment. Students felt less confident in their ability to learn, pointing to the fact that students self assess themselves as less capable when engaged in multitasking.

Multitasking students typically predict lower scores on academic performance than on-task students. Experimental data of 34 students failed to indicate difference in quiz scores of those who used devices while listening to a lecture and those who did not; however, when asked to predict scores prior to taking a comprehension quiz, students who used their cell phones during lecture anticipated lower scores than students who did not (Elder, 2013). A more recent prediction study found similar results. Sixty 
college students predicted results of media multitasking while completing a homework assignment in various media availability conditions (Calderwood, Green, Joy-Gaba, \& Moloney, 2016). Participants received instructions to bring $3 \mathrm{~h}$ of homework of different subjects and any media items of their choice to the laboratory. Upon arrival, participants were instructed to complete their homework as they typically would. At the beginning of each hour, participants completed a 34-item measure of state affect, fatigue, self-efficacy, and positive motivation. Students predicted media use to result in lower negative affect and less self-control. While the direction of their predictions was accurate, students underestimated the effect of media multitasking on their performance.

Although students recognize potential negative impact of multitasking with media, they continue to do it. Survey responses assessing frequency and duration of media use in an introductory psychology class indicate that students discount the effect of media on learning over time (Ravizza, Hambrick, \& Fenn, 2014). Five-hundred and eight students completed a nine-question survey assessing the frequency and duration of texting, using Facebook, checking email, and non-class related Internet use during lectures. For each media, participants reported how frequently they used the technology and estimated the average amount of time spent on these activities during lecture. The final question examined the degree to which students perceived internet and phone use to affect their learning. Students demonstrate poor awareness of how media multitasking affects their learning. Kraushaar and Novak (2010) reported students underreported email multitasking by $7 \%$ and IM by $40 \%$. In Elder's (2013) study, questionnaire data of 88 college students' beliefs indicated an acceptance of in-class use and neutral beliefs about whether multitasking affects study time. Similarly, Clayson and Haley (2012) reported that $68 \%$ of students believed they could attend to a lecture and text at the same time, yet students who texted received lower grades. This suggests an incapability of students to make accurate and discerning decisions about multitasking while completing academic tasks.

Another study combining survey with experimental methods found that participants predicted losing close to 30\% accuracy on a quiz when using cell phones and indeed lost close to $30 \%$ when texting (Froese et al., 2010). Non-multitasking students feel more confident in their ability to predict scores accurately. In an experiment asking lecture-only and lecture-texting groups to predict their performance on a quiz assessing lecture content retention, the lecture-only group had higher scores on the quiz and felt more confident in their predictions (Gingerich \& Lineweaver, 2014). This, coupled with data regarding multitaskers' metacognitive beliefs, indicates that students are poor at recognizing and regulating inhibitors of performance.

Self-regulation requires conscious personal management and guiding of one's thoughts, behaviors, and feelings to achieve goals. Although there is some evidence that students adjust reading time, adolescents do not effectively self-regulate their media multitasking. Despite students readily acknowledging multitasking divides attention, media multitasking persists. Furthermore, students do not accurately predict its impact on task performance. A possible explanation is that multitasking while studying hinders the implementation of an appropriate learning strategy. Thus, media multitasking inhibits metacognition and self-regulation, preventing implementation of the appropriate learning strategy and reducing performance (Lee, Cho, Kim, \& Noh, 2015). 
Wei, Wang, and Klausner (2012) examined the impact of texting on students' cognitive learning with surveys of 190 college students. They found that college students' self-regulation negatively related to text messaging use during class; text messaging use during class negatively related to student sustained attention to classroom learning. Structural equation modeling analysis found texting during class to partially mediate effect of students' self-regulation on their sustained attention to classroom learning. Moreover, students' sustained attention fully mediates effect of in-class texting on experience-oriented learning. Thus, college students with high levels of self-regulation are less likely to text during class and more likely to maintain attention to classroom learning.

Multitasking reduces efficiency when performing academic tasks. Survey data of 361 college students who reported texting while doing homework, also reported spending more time studying outside of class, as multitasking contributes to inefficient study habits (Bellur et al., 2015). Participants who IMed while completing a reading task took significantly longer to complete the task (12.56 min compared to $8.23 \mathrm{~min}$ by nonmultitasking participants; Fox et al., 2009). In a similar study of the same experimental design, participants who IM while reading took $22 \%-59 \%$ longer to complete the task than those who IMed before reading or did not IM at all, even after deducting the time spent on Instant Messaging (Bowman, Levine, Waite, \& Gendron, 2010).

Although multitasking reduces efficiency, comprehension is not always affected. Participants may re-read certain parts of the article after interruption; although this increases reading time, it can make up for deficits in comprehension (Bowman et al,, 2010; Fox et al., 2009). In both of the aforementioned studies, although statistically significant differences were found in student time to complete the reading passage, comprehension was not harmed. Thus, students who are particularly metacognitive can overcome the effects of media multitasking on comprehension, especially when students control the pace of presented information. Comparisons of various multitasking conditions indicate this (Pashler, Kang, \& Ip, 2013). Participants read or listened to several short historical narratives while engaging in five to eight brief conversations simulating Instant Messaging in various conditions: (1) reading narratives; (2) audio narratives paused during message conversing; and (3) audio narratives not paused during message conversing. When reading narratives and attending to messages, multitasking marginally increased reading time but comprehension was not significantly affected. This repeated when narratives were presented in audio format and paused during messaging. However, when audio narratives did not pause, interruptions reduced comprehension performance. This may be suggestive of the trained attention hypothesis, which holds that frequent media multitasking could have a positive effect on cognitive control via eventual training and improvement of control processes.

The role of media multitasking on comprehension is dependent on self-regulation and self-awareness. Students who are particularly metacognitive or self-aware recognized deficits in comprehension upon returning to the primary task and subsequently re-read portions of the article after interruption. Although this increases reading time, it can make up for deficits in comprehension. While this is acceptable for academic tasks which are not completed under time-constraints such as homework assignments, multitasking during time-contingent academic tasks such as an essay or in-class lecture is problematic; the student cannot make up for deficits in comprehension via repeated 
exposure to the text without costs to performance. Thus, the type of work matters when examining the impact of media multitasking on performance. Some research suggests that regardless of context, whether learning in class, studying outside class, or engaging in homework alone or in collaboration, most students tend to multitask with smartphones (Jacobsen \& Forste, 2011; Junco, 2012). Although media, such as smartphones, provide access to educational resources and facilitate collaboration, studies indicate that technology-related distractions are negatively related to homework effort and environment (Chan, Walker, \& Gleaves, 2015; Hawi \& Samaha, 2016; Xu, 2015).

\section{Discussion}

Media multitasking is detrimental to academic capacities of college learners. Cognitive effects of media multitasking were found to be negative across a range of outcomes (see Table 1). Inside of the classroom, media multitasking is negatively associated with GPA, test performance, information recall, comprehension, and note-taking, especially when students multitask to engage in off task activities. These effects are not mediated by achievement level and negatively impact non-multitasking peers. Outside of the classroom, media multitasking is also tied to poorer classroom performance along with students predicting less confidence and lower scores. Furthermore, media multitasking is negatively associated with efficiency and reading comprehension. These effects are mediated by self-regulation and metacognition; students may account for deficits in comprehension by rereading, thus improving comprehension but diminishing efficiency. This is indicative of information processing theory, because attention is a limited resource, media multitasking hastens depletion of attentional resources, thus diminishing performance on the primary task.

One primary differential distinguishing the influence of media multitasking on academic performance out of class versus in-class is that the lack of time contingencies or instructional proctorship heighten the mediating influence of metacognition and selfawareness. As seen in research examining the effect of media multitasking on reading comprehension, students can account for deficits in performance by re-reading or redoing a task when working outside of the classroom. This cannot occur in the classroom due to time constraints, especially when the instructor controls the pace of instruction and under largely lecture format contexts. This suggests the need for further research examining the role of various educational contexts to understand more fully the effects of media multitasking on academic performance. Most existing research was accomplished in college classes utilizing a traditional, lecture format. These teacher- directed instructional contexts do not allow the student to control the rate nor amount of incoming information. Whether nontraditional methods of instruction such as

Table 1 Cognitive effects of media multitasking on academic performance

\begin{tabular}{ll}
\hline Negative multitasking effects & Number of studies demonstrating effect \\
\hline G.P.A. & 15 \\
Test performance/recall & 15 \\
Comprehension & 6 \\
Note-taking & 3 \\
Self-regulation & 10 \\
Efficiency & 4 \\
\hline
\end{tabular}


flipped classrooms, collaborative learning, or participatory learning exhibit different relationships with media multitasking is largely unexplored to date. These nontraditional formats are increasingly popular and may be more conducive to successful media multitasking in academic arenas since students can direct and regulate their attention as they control the amount and pace of incoming information. Conversely, media multitasking while engaging in these alternate instructional structures may reveal a lack of depth of student thinking and understanding since they require them to synthesize information from discussions. Thus, further research in this area is needed to fully investigate effects of media multitasking in a variety of instructional formats.

In addition to types of instructional contexts, further research examining the types of academic tasks and assessments, including assignment formats, levels of difficulty, and interest level, is warranted, especially when students are studying on their own. These may be factors that account for variations in the relationship between students' sustained attention, multitasking behaviors, and measured academic performance. Students pay attention, potentially engage in multitasking, and study differently depending on nature of tasks demanded of them and their motivations and perceived ability in completing them. The frequency, duration, and conditions under which students choose to multitask or not are important issues to ponder. Hence, to gain a better understanding of the effects of multitasking for college students, additional investigations of types of tasks and motivation are required.

Research on the relationship of metacognition and the effects of multitasking on reading comprehension illustrate the intersection of self-regulation and working memory. Visual working memory theories examine the role of self-regulation in selecting and maintaining task-relevant visual targets. Thus, self-awareness is critical in mitigating the effects of media multitasking. Yet, students do not effectively self-regulate their media multitasking and are poor at recognizing and regulating inhibitors of performance. While students recognize that multitasking divides their attention, media multitasking reduces both accuracy and confidence in predicting impact on task performance. Self-regulation is an important skill in addressing multitasking and is an area of interest for future research, as students are not successful in managing their multitasking to avoid inhibiting performance or efficiency. Research on methods to foster student recognition of the deleterious effects of media multitasking, as well as development of self-regulation skills, can offer insight to classroom technology policy and instruction.

\section{Implications}

Technology does offer benefits to the educational experience. In balancing these benefits with the negative effects of media multitasking, the issue becomes one of appropriate implementation of technology in the classroom. Fostering development of self-monitoring skills in students thus becomes critical. Research on laptop use in the classroom reveals effects dependent upon classroom environment (i.e., structured vs. unstructured use of technology) and the way in which the laptop was used (i.e., on-task vs. off-task multitasking). Structured tasks with specific and clearly indicated requirements for technology usage are less likely to catalyze off-task multitasking than unstructured tasks. Complex tasks emphasizing project-based, constructivist learning encouraged on-task laptop use, as opposed to recitation or drill-and-practice tasks that led to off-task usage (Mouza, 2008). As 
demonstrated by Judd and Kennedy (2011), a student with a specific goal and sufficient motivation, such as studying for an upcoming exam in a difficult class, is less likely to multitask. On the other hand, students with less consequential goals, such as communicating with friends for leisure via Facebook or email, are more likely to multitask. Thus, complex activities will promote task-relevant technology usage,employing the many benefits technology offers, while diminishing opportunities to multitask. Class observation indicated that laptops may enhance student-centered, hands-on, and exploratory learning, as well as increase student-to-student and student-to-instructor interactions (Barak, Lipson, \& Lerman, 2006). Clearly stated mobile phone policy on a syllabus can decrease phone use in the classroom (Chen \& Yan, 2016). Suggested methods include employing classroom curriculum in which laptops are incorporated strategically with a pedagogy to maximize potential benefits and minimize distractions. With careful implementation, these methods potentially harness the positive effects of educational technology while diminishing the negative effects of media multitasking.

For the most part, students do not recognize the extent of the negative consequences of media multitasking on academic performance. College students commonly report that multitasking increases productivity (Lin et al., 2015). Because research indicates that student media multitasking extends to outside of the classroom, and because studies establish the negative impact of multitasking on academic performance, students should be advised to carefully monitor their technology use when working on school assignments. Requiring schoolwork to be complete before using technology, keeping technology in communal areas, or providing other measures to discourage off-task multitasking help facilitate learning and efficient studying. Likewise, choosing to study in communal areas, such as the library, may facilitate on-task engagement. Students are not particularly metacognitive in relation to their abilities to multitask, nor to the effects of media multitasking. There is a tendency of students to overestimate their multitasking ability. This indicates the need for educators and parents to encourage students' self-regulation of laptop and cell phone multitasking behaviors, and the importance of fostering student self-efficacy and learning motivations.

Though educators promote productive use of classroom technology with policies limiting off-task media multitasking, the collegiate education system relies on the increasing independence and self-regulation on the part of students. Educating students about the impacts of media multitasking on academic performance will potentially foster selfawareness, and perhaps self-regulation of multitasking habits. Self-regulation of multitasking habits is a necessary skillset for the modern student, and upon graduation, the modern professional. Developing self-regulation skills and positive technology habits while in school prepares the student for balancing the modern workplace. This may redefine the problematic variables of the educational technology debate, shifting the criticism from technology implementation to the manner in which usage is monitored.

Abbreviations

GPA: Grade Point Average; IM: Instant Message

Acknowledgements

Not applicable.

Funding

This review did not receive funding. 
Availability of data and materials

Not applicable-literature review.

\section{Authors' contributions}

Conception and design of review: KEM, AE. Acquisition of reviewed literature: KEM. Analysis and/or interpretation of literature reviewed: KEM, AE. Drafting manuscript: KEM. Revising manuscript: KEM, AE. Approval of version of manuscript to be published: KEM, AE. Both authors read and approved the final manuscript.

\section{Ethics approval and consent to participate}

Not applicable.

\section{Consent for publication}

Not applicable.

\section{Competing interests}

The authors declare that they have no competing interests.

\section{Publisher's Note}

Springer Nature remains neutral with regard to jurisdictional claims in published maps and institutional affiliations.

\section{Author details}

'Department of Educational Studies in Psychology, Research Methodology, and Counseling, University of Alabama, Tuscaloosa, AL 07203, USA. ${ }^{2}$ Department of Counseling, Educational Psychology, and Foundations, Mississippi State University, Starkville, MS 39762, USA.

Received: 8 August 2017 Accepted: 4 February 2018

Published online: 27 February 2018

\section{References}

Al-Menayes, J. J. (2015). Social media use, engagement, and addiction as predictors of academic performance. International Journal of Psychological Studies, 7, 86-94.

Alzahabi, R., \& Becker, M. W. (2013). The association between media multitasking, task-switching, and dual-task performance. Journal of Experimental Psychology: Human Perception and Performance, 39(5), 1485-1495.

Barak, M., Lipson, A., \& Lerman, S. (2006). Wireless laptops as means for promoting active learning in large lecture halls. Journal of Research on Technology in Education, 38(3), 245-263.

Bellur, S., Nowak, K. L., \& Hull, K. S. (2015). Make it our time: In class multitaskers have lower academic performance. Computers in Human Behavior, 53, 63-70.

Bowman, L. L., Levine, L. E., Waite, B. M., \& Gendron, M. S. (2010). Can students really multitask? An experimental study of instant messaging while reading. Computers \& Education, 54(4), 927-931.

Broadbent, D. (1958). Perception and communication. London: Pergamon Press.

Brooks, S. (2015). Does personal social media usage affect efficiency and well-being? Computers in Human Behavior, 46, 26-37.

Cain, M. S., Leonard, J. A., Gabrieli, J. D., \& Finn, A. S. (2016). Media multitasking in adolescence. Psychonomic Bulletin \& Review, 23(6), 1932-1941. https://doi.org/10.3758/s13423-016-1036-3.

Cain, M. S., \& Mitroff, S. R. (2011). Distractor filtering in media multitaskers. Perception, 40, 1183-1192.

Calderwood, C., Green, J. D., Joy-Gaba, J. A., \& Moloney, J. M. (2016). Forecasting errors in student media multitasking during homework completion. Computers \& Education, 94, 37-48. https://doi.org/10.1016/j.compedu.2015.10.021.

Chan, N. N., Walker, C., \& Gleaves, A. (2015). An exploration of students' lived experiences of using smartphones in diverse learning contexts using a hermeneutic phenomenological approach. Computers \& Education, 82, 96-106.

Chen, Q., \& Yan, Z. (2016). Does multitasking with mobile phones affect learning? A review. Computers in Human Behavior, 54, 34-42.

Chinchanachokchai, S., Duff, B. R., \& Sar, S. (2015). The effect of multitasking on time perception, enjoyment, and ad evaluation. Computers in Human Behavior, 45, 185-191.

Clayson, D. E., \& Haley, D. A. (2012). An introduction to multitasking and texting: Prevalence and impact on grades and GPA in marketing classes. Journal of Marketing Education, 35(1), 26-40.

Conard, M. A., \& Marsh, R. F. (2014). Interest level improves learning but does not moderate the effects of interruptions: An experiment using simultaneous multitasking. Learning and Individual Differences, 30, 112-117.

Courage, M. L., Bakhtiar, A., Fitzpatrick, C., Kenny, S., \& Brandeau, K. (2015). Growing up multitasking: The costs and benefits for cognitive development. Developmental Review, 35, 5-41.

Downs, E., Tran, A., McMenemy, R., \& Abegaze, N. (2015). Exam performance and attitudes toward multitasking in six, multimedia-multitasking classroom environments. Computers \& Education, 86, 250-259.

Elder, A. D. (2013). College students' cell phone use, beliefs, and effects on their learning. College Student Journal, 47, $585-592$.

Ellis, Y., Daniels, B., \& Jauregui, A. (2010). The effect of multitasking on the grade performance of business students. Research in Higher Education Journal, 8, 1-10.

Fox, A. B., Rosen, J., \& Crawford, M. (2009). Distractions, distractions: Does instant messaging affect college students' performance on a concurrent reading comprehension task? Cyberpsychology \& Behavior, 12(1), 51-53.

Fried, C. B. (2008). In-class laptop use and its effects on student learning. Computers \& Education, 50(3), 906-914.

Froese, A. D., Carpenter, C. N., Inman, D. A., Schooley, J. R., Barnes, R. B., Brecht, P. W., \& Chacon, J. D. (2010). Effects of classroom cell phone use on expected and actual learning. College Student Journal, 46, 323-332. 
Gingerich, A. C., \& Lineweaver, T. T. (2014). OMG! Texting in class = U fail:(empirical evidence that text messaging during class disrupts comprehension. Teaching of Psychology, 41(1), 44-51. https://doi.org/10.1177/ 0098628313514177.

Hawi, N. S., \& Samaha, M. (2016). To excel or not to excel: Strong evidence on the adverse effect of smartphone addiction on academic performance. Computers \& Education, 98, 81-89.

Hembrooke, H., \& Gay, G. (2003). The laptop and the lecture: The effects of multitasking in learning environments. Journal of Computing in Higher Education, 15(1), 46-64. https://doi.org/10.1007/bf02940852.

Hollingworth, A., \& Beck, V. M. (2016). Memory-based attention capture when multiple items are maintained in visual working memory. Journal of Experimental Psychology: Human Perception and Performance, 42(7), 911-917. https://doi.org/10.1037/xhp0000230.

Hwang, Y., Kim, H., \& Jeong, S. (2014). Why do media users multitask?: Motives for general, medium-specific, and content-specific types of multitasking. Computers in Human Behavior, 36, 542-548.

Jacobsen, W. C., \& Forste, R. (2011). The wired generation: Academic and social outcomes of electronic media use among university students. Cyberpsychology, Behavior and Social Networking, 14(5), 275-280.

Judd, T. (2014). Making sense of multitasking: The role of Facebook. Computers \& Education, 70, 194-202.

Judd, T., \& Kennedy, G. (2011). Measurement and evidence of computer-based task switching and multitasking by 'net generation' students. Computers \& Education, 56(3), 625-631.

Junco, R. (2012). Too much face and not enough books: The relationship between multiple indices of Facebook use and academic performance. Computers in Human Behavior, 28(1), 187-198.

Junco, R., \& Cotten, S. R. (2012). No a 4 U: The relationship between multitasking and academic performance. Computers \& Education, 59(2), 505-514.

Karpinski, A. C., Kirschner, P. A., Ozer, I., Mellott, J. A., \& Ochwo, P. (2013). An exploration of social networking site use, multitasking, and academic performance among United States and European university students. Computers in Human Behavior, 29, 1182-1192.

Kraushaar, J. M., \& Novak, D. C. (2010). Examining the effects of student multitasking with laptops during the lecture. Journal of Information Systems Education, 21, 241-251.

Kuznekoff, J. H., Munz, S., \& Titsworth, S. (2015). Mobile phones in the classroom: Examining the effects of texting, twitter, and message content on student learning. Communication Education, 64(3), 344-365.

Kuznekoff, J. H., \& Titsworth, S. (2013). The impact of mobile phone usage on student learning. Communication Education, 62(3), 233-252.

Lee, J., Cho, B., Kim, Y., \& Noh, J. (2015). Smartphone addiction in university students and its implication for learning. In: Chen, G., Kumar, V., Kinshuk, Huang R., Kong, S. (eds) Emerging issues in smart learning. Springer, Berlin, Heidelberg.

Lepp, A., Barkley, J. E., \& Karpinski, A. C. (2015). The relationship between cell phone use and academic performance in a sample of U.S. college students. SAGE Open, 5(1), 1-9.

Lin, L., Cockerham, D., Chang, Z., \& Natividad, G. (2015). Task speed and accuracy decrease when multitasking. Technology, Knowledge and Learning, 21(3), 307-323. https://doi.org/10.1007/s10758-015-9266-4.

Lau, Wilfred W.F. (2017) Effects of social media usage and social media multitasking on the academic performance of university students. Computers in Human Behavior 68:286-291.

Maslovat, D., Chua, R., Spencer, H. C., Forgaard, C. J., Carlsen, A. N., \& Franks, I. M. (2013). Evidence for a response preparation bottleneck during dual-task performance: Effect of a startling acoustic stimulus on the psychological refractory period. Acta Psychologica, 144(3), 481-487.

McDonald, S. E. (2013). The effects and predictor value of in-class texting behavior on final course grades. College Student Journal, 47, 34-40.

Miller, E. K., \& Cohen, J. D. (2001). An integrative theory of prefrontal cortex function. Annual Review of Neuroscience, 24(1), 167-202. https://doi.org/10.1146/annurev.neuro.24.1.167.

Mouza, C. (2008). Learning with laptops: Implementation and outcomes in an urban, under-privileged school. Journal of Research on Technology in Education, 40(4), 447-472.

Ophir, E., Nass, C., \& Wagner, A. D. (2009). Cognitive control in media multitaskers. Proceedings of the National Academy of Sciences, 106(37), 15583-15587.

Pashler, H., Kang, S. H. K., \& Ip, R. Y. (2013). Does multitasking impair studying? Depends on timing. Applied Cognitive Psychology, 27, 593-599.

Patterson, M. C. (2017). A naturalistic investigation of media multitasking while studying and the effects on exam performance. Society for the Teaching of Psychology, 44, 51-57.

Ravizza, S. M., Hambrick, D. Z., \& Fenn, K. M. (2014). Non-academic internet use in the classroom is negatively related to classroom learning regardless of intellectual ability. Computers \& Education, 78, 109-114.

Redick, T. S. (2016). On the relation of working memory and multitasking: Memory span and synthetic work performance. Journal of Applied Research in Memory and Cognition, 5(4), 401-409. https://doi.org/10.1016/j.jarmac.2016.05.003.

Roberts, D. F., Foehr, U. G., Rideout, V. (2010). Generation M²: Media in the lives of 8- to 18-year olds. Kaiser Family Foundation.

Rosen, L., Lim, A., Carrier, M., \& Cheever, N. (2011). An empirical examination of the educational impact of text messageinduced task switching in the classroom: Educational implications and strategies to enhance learning. Revista de Psicología Educativa, 17(2), 163-177. https://doi.org/10.5093/ed2011v17n2a4.

Sana, F., Weston, T., \& Cepeda, N. J. (2013). Laptop multitasking hinders classroom learning for both users and nearby peers. Computers \& Education, 62, 24-31.

Subrahmanyam, K., Michikyan, M., Clemmons, C., Carrillo, R., Uhls, Y. T., \& Greenfield, P. M. (2013). Learning from paper, learning from screens: Impact of screen reading and multitasking conditions on reading and writing among college students. International Journal of Cyber Behavior, Psychology, and Learning, 3(4), 1-27.

Uncapher, M. R., Thieu, M. K., \& Wagner, A. D. (2016). Media multitasking and memory: Differences in working memory and long-term memory. Psychonomic Bulletin and Review, 23, 483-490.

Van dur Schuur, W. A., Baumgartner, S. E., Sumter, S. R., \& Valkenburg, P. M. (2015). The consequences of media multitasking for youth: A review. Computers in Human Behavior, 53, 204-215. 
Walsh, J. L., Fielder, R. L., Carey, K. B., \& Carey, M. P. (2013). Female college students' media use and academic outcomes: Results from a longitudinal cohort study. Emerging Adulthood, 1, 219-232.

Wei, F. F., Wang, Y. K., \& Klausner, M. (2012). Rethinking college students' self-regulation and sustained attention: Does text messaging during class influence cognitive learning? Communication Education, 61(3), 185-204. https://doi.org/10.1080/03634523.2012.672755.

Wood, E., Zivcakova, L., Gentile, P., Archer, K., Pasquale, D. D., \& Nosko, A. (2012). Examining the impact of off-task multitasking with technology on real-time classroom learning. Computers \& Education, 58(1), 365-374.

Wurst, C., Smarkola, C., \& Gaffney, M. A. (2008). Ubiquitous laptop usage in higher education: Effects on student achievement, student satisfaction, and constructivist measures in honors and traditional classrooms. Computers \& Education, 51(4), 1766-1783. https://doi.org/10.1016/j.compedu.2008.05.006.

$\mathrm{Xu}, \mathrm{J}$. (2015). Investigating factors that influence conventional distraction and tech-related distraction in math homework. Computers \& Education, 81, 304-314.

Zhang, W. (2015). Learning variables, in-class laptop multitasking and academic performance: A path analysis. Computers \& Education, 81, 82-88. https://doi.org/10.1016/j.compedu.2014.09.012.

Submit your manuscript to a SpringerOpen ${ }^{\circ}$ journal and benefit from:

- Convenient online submission

- Rigorous peer review

- Open access: articles freely available online

- High visibility within the field

- Retaining the copyright to your article

Submit your next manuscript at $\gg$ springeropen.com 